\title{
The cohort of young Danish farmers - A longitudinal study of the health effects of farming exposure
}

This article was published in the following Dove Press journal:

Clinical Epidemiology

27 March 2010

Number of times this article has been viewed

\section{Grethe Elholm ${ }^{1,2}$ \\ Øyvind Omland ${ }^{1,2}$ \\ Vivi Schlünssen' \\ Charlotte Hjort ${ }^{3}$ \\ loannis Basinas' \\ Torben Sigsgaard'}

'Department of Environmental and Occupational Medicine, Institute of Public Health, Aarhus University; ${ }^{2}$ Department of Occupational Health, Aalborg Hospital, Aarhus University Hospital; ${ }^{3}$ Regional Hospital Viborg, Skive, Kjellerup
Correspondence: Grethe Elholm Institute of Public Health, Department of Environmental and Occupational Health, Aarhus University, Bartholins Alle 2, Building 1260, 8000 Aarhus C, Denmark $\mathrm{Tel}+45221 \mathrm{I} 2044$

Fax +4589426199

Email gelh@mil.au.dk

\begin{abstract}
Working in agriculture poses a serious risk for development of respiratory diseases, especially when working in animal housing. Animal workers are exposed to a mixture of organic and inorganic dust together with fumes and gases, including allergens and microbial-associated molecular patterns with a potentially major impact on respiratory health and the immune system. Exposure to microbial agents in animal housing is associated with an increased prevalence of respiratory symptoms, including bronchial hyperresponsiveness, accelerated lung function decline, and neutrophil-mediated inflammation. These clinical findings are often seen without IgE-mediated sensitization. In fact it has been found in recent studies that the prevalence of atopic sensitization and atopic asthma is low among farmers compared with other populations. The SUS study was designed to identify the type and occurrence of respiratory symptoms and disease, and to investigate risk factors for respiratory disorders and changes in lung function among young farming students. The cohort of young Danish farmers was established in 1992/1994 and followed up in 2007/2008 with a participation rate of $51.7 \%$. The cohort consists of 1734 male farming students, 230 female farming students, and 407 army recruits as controls.
\end{abstract}

Keywords: respiratory health, atopy, asthma, rhinitis, lung function, farming environment, occupational exposure, cohort study

\section{Introduction}

The farming industry is an important export industry in Denmark, as well as in many other Western countries. Investigation of the occupational health hazards of farming is therefore of considerable interest to both the farming industry and the Danish community. Despite major changes in farming during recent decades, and an increased awareness of the potential hazards from agricultural exposure, the risk of lung diseases and loss of lung function in farm workers is still considerable. ${ }^{1}$

Working in agriculture poses a serious risk for development of respiratory diseases, especially when working in animal housing. Animal housing workers are exposed to a mixture of organic and inorganic dust together with fumes and gases, including allergens and microbial-associated molecular patterns (MAMP) with a potentially major impact on respiratory health and the immune system. ${ }^{2,3}$

Respiratory health effects in farming, especially in swine-confinement workers are well described. Exposure to microbial agents in a swine-confinement environment is associated with an increased prevalence of respiratory symptoms, including bronchial hyperresponsiveness (BHR), accelerated lung function decline, and neutrophil-mediated inflammation, ${ }^{2,4}$ without IgE-mediated sensitization against swine and food allergens. In fact, it has been found in recent studies that 
the prevalence of atopic sensitization and atopic asthma is low in farmers compared with other populations. A low prevalence of allergy and allergic asthma has been found in studies of children ${ }^{5}$ and young adults ${ }^{6}$ born and raised on a farm, ${ }^{6}$ as well as in adult farmers exposed to the same environment. ${ }^{7,8}$ The general respiratory health of any farmer is also dependent on individual genetic makeup. It has been found that toll-like receptor (TLR) gene polymorphisms are important determinants of susceptibility to asthma and allergy. ${ }^{9}$ TLRs are an evolutionarily conserved group of molecules which are a part of the innate immune system. TLRs are expressed in antigen-presenting cells and epithelial cells, and have microbial molecules as ligands. ${ }^{10}$

The SUS study was designed to identify the type and occurrence of respiratory symptoms, measure lung function, and investigate risk factors for respiratory disorders and annual rates of change in lung function among young farming students. Data were analyzed both as a cross-sectional study at baseline and as part of a case-control follow-up study over five years.

Most of the research in this area has been in the form of cross-sectional studies. Few cohort studies have been reported thus far and, to our knowledge, no studies have addressed the respiratory health of people entering the farming industry at a young age. Although sensitization to storage mites and other airborne allergens has been described, reports on sensitization to hog antigens have been inconclusive concerning the extent to which allergies contribute to the increased prevalence of respiratory symptoms in farm workers.

In an attempt to clarify the contribution of farming exposure to respiratory disease and loss of lung function over time, the SUS study was followed up with the SUS12 study. During the SUS12 study, the initial SUS cohort was re-examined. The SUS12 follow-up study in combination with the original data from the SUS study now allows for longitudinal investigation of risk factors and occupational influence on the development of respiratory disease. Furthermore, it is possible to investigate potential gene-environment interactions related to farming exposure. The SUS project group is collaborating with the European research group GABRIEL, which is focusing on genes important for asthma and geneenvironment interactions among children and working adult populations, using a whole genome analysis and candidate gene approach (http://www.gabriel-fp6.org/).

Despite the wealth of research on sensitisation, lung disease, and lung function done in farm workers in the last three decades, important questions remain unanswered. There is no unequivocal documentation of which dust components in the exposure have adverse health effects. Incidence studies of health outcomes which include reliable, representative, and valid exposure assessments have yet to be published. Incidence studies with asthma and COPD as outcomes still need to be performed. The question of phenotypes and genotypes of asthma and the association with exposure is yet to be fully answered. There is currently no knowledge of any time window for the "protective effect" of being raised on a farm regarding sensitisation, inflammation, and lung disease. Does childhood exposure to rural allergens confer an overall protection, or does the individual experience an increase in sensitization with time in a dose-dependent manner? Does the protective effect of farming exposure on allergic sensitization continue over time? Additionally, how can a supposed high allergen exposure convey loss of sensitization? What is the association between changes in sensitization and the risk of respiratory disorders? What influence does occupational activation of MAMPs have on the diseases encountered in farming?

\section{Trial design}

This research included both a cohort study which was a crosssectional comparison of type and occurrence of respiratory symptoms in farming students and nonfarming rural controls and a longitudinal study which investigated new cases of respiratory disease over time in relation to farming exposure.

\section{Study population}

The cross-sectional study consisted of 2478 farming students identified during their second stay at the farming schools in Denmark during the period February 1992 to February 1994. of 2004 students $(81 \%)$ who indicated that they wished to participate, $40(2 \%)$ did not attend for their baseline clinical assessment. The final group consisted of 1734 male and 230 female farming students. Army recruits were invited to participate as controls, provided that they came from rural areas but were not planning on becoming farmers. There were 967 eligible army recruits of whom 592 (61\%) agreed to participate. A random sample of 407 of these recruits were chosen and used in the study. The demographics of the cohort are presented in Table 1 and their lung function and respiratory symptoms are summarized in Table 2.

\section{Follow-up}

The subjects were investigated at baseline and then followed up with annual questionnaires and phone interviews for five years. All new respiratory symptoms were recorded. All subjects reporting new asthma symptoms and a matched 
Table I Demographic and exposure characteristics of the cohort $(n=2,37$ I)

\begin{tabular}{llll}
\hline & $\begin{array}{l}\text { Female students } \\
(\mathbf{n}=\mathbf{2 3 2})\end{array}$ & $\begin{array}{l}\text { Male students } \\
(\mathbf{n}=1734)\end{array}$ & $\begin{array}{l}\text { Male controls } \\
(\mathbf{n}=\mathbf{4 0 5})\end{array}$ \\
\hline Demographics & $19.1(17-47)$ & $18.5(17-49)$ & $19.0(18-23)$ \\
Age $(\mathrm{yrs})^{\S}$ & $169(149-192)$ & $183(161-198)$ & $181(166-197)$ \\
Height $(\mathrm{cm})^{\S}$ & $73(32)$ & $554(32)$ & $136(34)$ \\
Smokers* & & & $0(0-65)$ \\
Exposures & $37(0-72)$ & $40(0-100)$ & $10(3)$ \\
Hours farm work/week & $67(29)$ & $433(25)$ & $18(4)$ \\
Work with swine* & $66(28)$ & $575(34)$ & $13(3)$ \\
Work with cattle* & $22(10)$ & $23 \mid(13)$ & $64(16)$ \\
Work with swine and cattle* & $89(39)$ & $1125(66)$ & \\
Field work* & & & \\
\hline
\end{tabular}

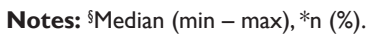

control group without symptoms were offered a clinical assessment to establish a diagnosis. In 2007 a comprehensive follow-up of the cohort was done using the Danish Civil Registration System to track new addresses, deaths, and emigration in the cohort. Of the 2371 participants, 2262 were identified to have a new Danish address, while 26 had died, and 51 had emigrated or did not have a permanent address. Thirty-two subjects could not be identified, most often because of incorrect registration of their unique personal identity number during the baseline study.

\section{Measurements}

\section{Health outcome}

At baseline the original SUS questionnaire was used, and in SUS12 this was extended to include further questions from the European Community Respiratory Health Survey (http://www.ecrhs.org). Lung function was measured with a dry bellow spirometer and with a spirometer (MicroMedical ${ }^{\circledR}$; Lyngby Denmark). For the SUS12 study the software was transferred for use on portable computers using the Windows 2000 platform. BHR was recorded according to the Yan method ${ }^{11}$ with a calibrated DeVilbiss No 40 nebulizer (Devilbiss Healthcare, LLC, Johnstown, PA, USA) connected to an "artificial hand" which uses compressed air to produce a pressure pulse similar to that created by a hand. ${ }^{12}$ For skin prick tests (SPT), a panel of nine common inhalant allergens (grass, mugwort, horse, dog, cat, house dust mites, moulds [Alternaria alternata and Claudosporium herbarum], extended with three storage mites [Tyrophagus putrescentiae, Lepidoglyphus destructor, and Acarus siro], and swine and cow dander were used (Soluprick ${ }^{\circledR}$, ALK-Abello, Copenhagen, Denmark).

\section{Exposure data}

At baseline and annually for five consecutive years, questionnaire information about the number and type of housed animals and amount of work done in these settings was recorded for all subjects in the cohort. In the case-control

Table 2 Lung function and respiratory symptoms in the cohort

\begin{tabular}{|c|c|c|c|c|c|c|}
\hline & \multicolumn{2}{|c|}{ Female students } & \multicolumn{2}{|c|}{ Male students } & \multicolumn{2}{|c|}{ Male rural controls } \\
\hline & $\begin{array}{l}\text { Smokers } \\
(n=73)\end{array}$ & $\begin{array}{l}\text { Non-smokers } \\
(n=159)\end{array}$ & $\begin{array}{l}\text { Smokers } \\
(n=554)\end{array}$ & $\begin{array}{l}\text { Non-smokers } \\
(n=1 / 80)\end{array}$ & $\begin{array}{l}\text { Smokers } \\
(n=136)\end{array}$ & $\begin{array}{l}\text { Nonsmokers } \\
(n=269)\end{array}$ \\
\hline \multicolumn{7}{|c|}{ Lung function mean (SD) } \\
\hline $\mathrm{FEV}_{1}$ & $3.49( \pm 0.47)$ & $3.61( \pm 0.55)$ & $4.57( \pm 0.58)$ & $4.64( \pm 0.61)$ & $4.75( \pm 0.59)$ & $4.70( \pm 0.65)$ \\
\hline FVC & $4.04( \pm 0.55)$ & $4.14( \pm 0.67)$ & $5.48( \pm 0.68)$ & $5.42( \pm 0.72)$ & $5.57( \pm 0.69)$ & $5.50( \pm 0.78)$ \\
\hline \multicolumn{7}{|c|}{ Respiratory symtoms N (\%) } \\
\hline Asthma & $5(6.8)$ & $10(6.3)$ & $35(6.3)$ & $46(3.9)$ & $4(2.9)$ & II (4.I) \\
\hline BHR & $6(8.5)$ & $15(9.8)$ & $66(12.2)$ & $94(8.2)$ & $9(7.2)$ & $22(8.5)$ \\
\hline Hayfever & 14 (19.2) & $20(12.6)$ & $48(8.7)$ & $109(9.3)$ & $18(13.2)$ & $42(15.6)$ \\
\hline
\end{tabular}

\$Median (min - max), ${ }^{*}(\mathrm{n})$ may vary due to missing values (\%).

Abbreviation: BHR, bronchial hyperresponsiveness. 
study, detailed hygienic information was recorded on, eg, type of feeding systems, type of litter, use of respirators, and cleaning procedures.

In SUS12, a more comprehensive exposure assessment including personal measurements and exposure modeling has been applied. One hundred farms were randomly selected and stratified by type and size in a defined geographical area among the remaining active farming population of the initial SUS cohort. Approximately 250 farmers employed in the selected farms have been monitored during the summer and winter of 2008-2009. Full-shift personal inhalable dust samples (one in each season) are being collected on $37 \mathrm{~mm}$ glass fiber filters using GSP sampling heads at a flow rate of $3.5 \mathrm{~L} / \mathrm{min}$ from every farmer. Concurrently, farmers are asked to fill in a detailed diary regarding their working activities for one week in each period (14 days in total). Walk-through surveys and personal interviews are performed to collect information on technical parameters and farm characteristics with known or suspected influence on the levels of exposure. Models on associations between technical parameters, farm characteristics, working tasks and exposure (dust and MAMPs) including within- and between-worker variability will be developed using regression analysis based on linear mixed-effect models. The derived equations will be used along with questionnaire data on historical exposure and exposure information from two previous studies ${ }^{13,14}$ to estimate current and retrospective exposure in the follow-up study.

\section{Completeness of follow-up}

The cohort consists of 2371 participants; for the SUS12 study, only 2262 of these could be identified with an address in Denmark, because some of the participants had immigrated, died, or were simply lost to follow-up. Of the identifiable participants, only 1170 were available to be re-examined, representing an overall attrition rate of $51.7 \%$, which was attributable to several reasons, including subjects choosing not to participate in the follow-up study, failure to attend for their follow-up appointment, and/or not responding to letters or phone calls.

\section{Ongoing release of data}

The SUS study has so far lead to the publication of 13 peerreviewed articles, ${ }^{6,15-26}$ one thesis, ${ }^{27}$ and several presentations at international conferences. An overview of the 13 articles and the main findings is summarised in Table 3.

The study showed that sensitisation to mites, animal dander, and pollen was higher in controls than in farming school students. ${ }^{16}$ Analyses published in 2002 demonstrated a lower prevalence of allergic symptoms, BHR, and sensitisation measured with skin prick test, and specific

Table 3 Published articles originating from the SUS study

\begin{tabular}{|c|c|}
\hline References & Main findings \\
\hline 15 & The resistance of the mini-Wright flow meter causes less variation in recordings but reduce peak expiratory flow. \\
\hline 16 & $\begin{array}{l}\text { Skin prick tests to house dust and storage mites were more prevalent among controls compared with male and female } \\
\text { farming students; size of house dust mite weal and number of positive skin prick reactions were associated with } \mathrm{BHR} \text {. }\end{array}$ \\
\hline 17 & $\begin{array}{l}\text { No relation between asthma and farming exposure was seen, but lung function was slightly reduced in the male } \\
\text { farming students compared with male controls. Prevalence of asthma was related to smoking, female sex, and family } \\
\text { history of asthma and allergy. }\end{array}$ \\
\hline 18 & The shape of the maximum expiratory flow-volume curve reflects exposure in farming. \\
\hline 19 & $\mathrm{~S}$ and $\mathrm{Z} \alpha_{1}$-antitrypsin alleles are risk factors for BHR in young farmers indicating a gene/environment interaction. \\
\hline 20 & LDS using $\mathrm{FEV}_{1}$ is the best spirometric index to measure short time repeatability of histamine bronchial testing. \\
\hline 6 & $\begin{array}{l}\text { Farming students born and raised on a farm had lower prevalence of allergic symptoms, BHR, positive SPT, and } \\
\text { specific IgE than students raised on a farm. }\end{array}$ \\
\hline 21 & Selenium measured both in serum and urine is associated with mild asthma and atopy. \\
\hline 22 & $\begin{array}{l}\text { For asthmatics the time domain index } \alpha I_{75} \text { was found to discriminate better among the flow indices applied } \\
\text { whereas for BHR the LDS using FEV, was superior to other measures of } B H R \text {. }\end{array}$ \\
\hline 23 & CD3 levels in young farmers correlate with respirable dust exposure levels during work in swine-confinement housing. \\
\hline 24 & Exposure to work-related levels of swine dust upregulates CDI06 in human alveolar macrophages. \\
\hline 25 & $\begin{array}{l}\text { A single exposure to organic dust in non-naïve nonexposed volunteers induces long lasting symptoms of endotoxin } \\
\text { tolerance. }\end{array}$ \\
\hline 26 & $\begin{array}{l}\text { CDI4/-260 and CDI4/-65I promoter polymorphisms associated with atopy prevalence in young adults with farm } \\
\text { exposure. }\end{array}$ \\
\hline
\end{tabular}

Abbreviations: BHR, bronchial hyperresponsiveness; LDS, log dose slope; SPT, skin prick test. 
and total $\operatorname{IgE}$ in subjects raised on a farm, compared with upbringing elsewhere. ${ }^{6}$ As opposed to a possible protective effect of being raised on a farm, low concentrations of alpha1 antitrypsin and rare genotypes (ZZ, ZS, SS) were found to increase the risk of BHR, but only among the farming students, indicating a gene-environment interaction for the inflammatory asthma phenotype. ${ }^{19}$ Preliminary analyses using available exposure data from other sources have found a dose-response relationship between estimated exposure to total dust and new onset of asthma. ${ }^{28}$ Furthermore, the prevalence of chronic bronchitis, self-reported asthma with BHR, and BHR was low. The prevalence of self-reported asthma without BHR was high. Lung function was slightly lower in male farming students compared with controls. There was a weak or no association between smoking and respiratory symptoms as well as lung function. It was found that $\mathrm{FEV}_{1}$ was the best index to measure basal lung function in response to bronchial provocation.

The SUS study has contributed significantly to our understanding of the inflammatory mechanisms involved in the immune response to organic dust exposure. This was investigated by exposing the participants for three hours to a swine-confinement environment containing dust and endotoxin levels at the lower end of the exposure range for Danish and European farms. It was found that dust exposure activated the complement system. Particularly for the farming students, C3d plasma levels correlated with respirable dust. Acute exposure was also seen to lead to other weak systemic inflammatory responses. ${ }^{23}$ Further dust exposure studies suggest that there is a specific requirement for CD106 during inflammatory recruitment of monocytes in the human lung, ${ }^{24}$ and this has previously been shown to be the case in the murine lung. Endotoxin tolerance has previously been described in vitro and in animal studies as a mechanism that modifies the threshold at which immune response occurs. It has also been found that long-lasting endotoxin tolerance and immune suppression may be induced by brief exposure to dust concentrations in the medium-low range of occupational levels. ${ }^{25}$

The SUS study has furthermore been used to investigate the correlation between selenium levels and asthma and atopy. It was found that selenium in serum and urine is associated with mild asthma and atopy. ${ }^{21}$

The longitudinal study provides data for investigating the incidence of respiratory disease in a farming environment. These data will also enable investigation of the interactions between genes and the environment and elucidation of the risk factors involved in the development of new asthma cases. It will also be possible to investigate the effects of respiratory diseases on lung function, and identify the parameters that describe this change best. Finally it would be helpful to be able to estimate the effect of respiratory symptoms and disease on change of work environment for the individual.

\section{Strengths and weaknesses}

The SUS cohort affords a unique opportunity for a longitudinal investigation of the effect of farming exposure on lung function and respiratory symptoms. To our knowledge, this cohort is unique. As already mentioned, lung function and respiratory symptoms have been assessed in all study participants in both at the SUS and the SUS12. It will also be possible using these data to assess respiratory health in relation to specific farming exposure for each subject. Additionally, important information on potential gene-environment interaction is emerging from this research through the GABRIEL collaboration. However, a potential weakness of this research is the relatively high attrition rate of approximately $50 \%$, which might affect the significance of data generated by future statistical analyses.

\section{Access to data}

A website has been created (http://www.folkesundhed.au.dk/ mil/forskning/sus 12), where the status of the SUS12 project is regularly updated. Specific questions regarding the cohort or the SUS12 project can be addressed to either Professor Torben Sigsgaard (ts@mil.au.dk), Associate Professor Vivi Schlünssen (vs@mil.au.dk), Associate Professor Øyvind Omland (oo@rn.dk), or Senior Consultant Charlotte Hjort (c.hjort@dadlnet.dk).

\section{Acknowledgments}

The cohort study was set up by Charlotte Hjort, Torben Sigsgaard and Øyvind Omland from The Institute of Public Health at University of Aarhus, Denmark. Funding for the SUS study was from The Danish Agency for Science Technology and Innovation, The Danish Medical Research Council, The Danish Agricultural Research Council, Helsefonden, and the PC Petersen Foundation. In SUS12 Vivi Schlünssen joined the core group. The main contributors for the SUS12 study were The Danish Working Environment Research Fund, The Danish Research Council Aarhus University, and The Danish Lung Association. The authors wish to thank the farming students and the control subjects for their patience and enthusiasm, and the staff of the farming schools for their ongoing support. 


\section{Disclosure}

The author report no conflicts of interest in this work.

\section{References}

1. Omland O. Exposure and respiratory health in farming in temperate zones - a review of the literature. Ann Agric Environ Med. 2002;9(2): 119-136.

2. Heederik D, Sigsgaard T. Respiratory allergy in agricultural workers: Recent developments. Curr Opin Allergy Clin Immunol. 2005;5(2): 129-134.

3. Sigsgaard T, Heederik D. On the hygiene hypothesis: Regulation down, up, or sideways? J Allergy Clin Immunol. 2005;115(6):1325-1326.

4. Dosman JA, Lawson JA, Kirychuk SP, CormierY, Biem J, Koehncke N. Occupational asthma in newly employed workers in intensive swine confinement facilities. Eur Respir J. 2004;24(4):698-702.

5. Braun-Fahrlander C, Riedler J, Herz U, et al. Environmental exposure to endotoxin and its relation to asthma in school-age children. $N$ Engl J Med. 2002;347(12):869-877.

6. Portengen L, Sigsgaard T, Omland O, Hjort C, Heederik D, Doekes G. Low prevalence of atopy in young Danish farmers and farming students born and raised on a farm. Clin Exp Allergy. 2002;32(2):247-253.

7. Portengen L, Preller L, Tielen M, Doekes G, Heederik D. Endotoxin exposure and atopic sensitization in adult pig farmers. J Allergy Clin Immunol. 2005;115(4):797-802.

8. Eduard W, Omenaas E, Bakke PS, Douwes J, Heederik D. Atopic and non-atopic asthma in a farming and a general population. Am J Ind Med. 2004;46(4):396-399.

9. Eder W, Klimecki W, Yu L, et al. Toll-like receptor 2 as a major gene for asthma in children of European farmers. J Allergy Clin Immunol. 2004;113(3):482-488.

10. Imler JL, Hoffmann JA. Toll receptors in innate immunity. Trends Cell Biol. 2001;11(7):304-311.

11. Yan K, Salome C, Woolcock AJ. Rapid method for measurement of bronchial responsiveness. Thorax. 1983;38(10):760-765.

12. Schlunssen V, Pedersen OF, Molhave F, Skovfoged PR, Sigsgaard T. Metacholine challenge test "Yan method" applying an "artificial hand". 14th Annual Congress of the European Respiratory Society, Glasgow, Scotland, 4-8 Sep 2004.

13. Preller L, Kromhout H, Heederik D, Tielen MJ. Modeling long-term average exposure in occupational exposure-response analysis. Scand J Work Environ Health. 1995;21(6):504-512.

14. Takai H, Pedersen S, Johnsen JO, et al. Concentrations and emissions of airborne dust in livestock buildings in Northern Europe. J Agr Eng Res. 1998;70(1):59-77.
15. Pedersen OF, Rasmussen TR, Omland O, Sigsgaard T, Quanjer PH, Miller MR. Peak expiratory flow and the resistance of the mini-wright peak flow meter. Eur Respir J. 1996;9(4):828-833.

16. Sigsgaard T, Hjort C, Omland O, Miller MR, Pedersen OF. Respiratory health and allergy among young farmers and non-farming rural males in Denmark: The SUS Study. J Agromedicine. 2004;9(2):223-238.

17. Omland O, Sigsgaard T, Hjort C, Pedersen OF, Miller MR. Lung status in young Danish rurals: The effect of farming exposure on asthma-like symptoms and lung function. Eur Respir J. 1999;13(1):31-37.

18. Omland O, Sigsgaard T, Pedersen OF, Miller MR. The shape of the maximum expiratory flow-volume curve reflects exposure in farming. Ann Agric Environ Med. 2000;7(2):71-78.

19. Sigsgaard T, Brandslund I, Omland O, et al. S and Z alpha1-antitrypsin alleles are risk factors for bronchial hyperresponsiveness in young farmers: An example of gene/environment interaction. Eur Respir J. 2000;16(1):50-55.

20. Omland O, Miller MR, Sigsgaard T, Pedersen OF. The short-term repeatability of histamine bronchial testing in young males. The SUS study. Respir Med. 2001;95(4):287-291.

21. Omland O, Deguchi Y, Sigsgaard T, Hansen JC. Selenium serum and urine is associated to mild asthma and atopy. The SUS study. $J$ Trace Elem Med Biol. 2002;16(2):123-127.

22. Miller MR, Sigsgaard T, Omland O, Pedersen OF. Time domain and flow indices of bronchial hyperresponsiveness: Association with asthma symptoms, atopy and smoking. Eur Respir J. 2002;20(1):86-91.

23. Hoffmann HJ, Iversen M, Brandslund I, et al. Plasma C3d levels of young farmers correlate with respirable dust exposure levels during normal work in swine confinement buildings. Ann Agric Environ Med. 2003;10(1):53-60.

24. Hoffmann HJ, Iversen M, Takai H, Sigsgaard T, Omland O, Dahl R. Exposure to work-related levels of swine dust up-regulates CD106 on human alveolar macrophages. Am J Ind Med. 2004;46(4):378-380.

25. Hoffmann HJ, Iversen M, Sigsgaard T, et al. A single exposure to organic dust of non-naive non-exposed volunteers induces longlasting symptoms of endotoxin tolerance. Int Arch Allergy Immunol. 2005;138(2):121-126.

26. Smit LA, Bongers SI, Ruven HJ, et al. Atopy and new-onset asthma in young Danish farmers and CD14, TLR2, and TLR4 genetic polymorphisms: A nested case-control study. Clin Exp Allergy. 2007;37(11):1602-1608.

27. Omland O. Respiratory Health Among Danish Farming Students. Aarhus, Denmark: Faculty of Health Sciences, University of Aarhus; 2001.

28. Sigsgaard T, Omland O, Takai H, Pedersen S. Dust, endotoxin, and ammonia exposure and development of asthma, a pilot study. International Symposium of Dust Control in Animal Production Facilities, Aarhus, Denmark, 30 May-2 Jun, 1999.
Clinical Epidemiology

\section{Publish your work in this journal}

Clinical Epidemiology is an international, peer-reviewed, open access journal focusing on disease and drug epidemiology, identification of risk factors and screening procedures to develop optimal preventative initiatives and programs. Specific topics include: diagnosis, prognosis, treatment, screening, prevention, risk factor modification, systematic Submit your manuscript here: http://www.dovepress.com/clinical-epidemiology-journal
Dovepress

reviews, risk \& safety of medical interventions, epidemiology \& biostatical methods, evaluation of guidelines, translational medicine, health policies \& economic evaluations. The manuscript management system is completely online and includes a very quick and fair peer-review system, which is all easy to use. 